\title{
Las competencias estatales y de las Comunidades Autónomas en relación con el procedimiento administrativo
}

\author{
José Antonio Tardío Pato
}

\begin{abstract}
Sumario: I. INTRODUCCIÓN. II. PROCEDIMIENTOS ADMINISTRATIVOS GENERALES Y ESPECIALES. III. PROCEDIMIENTOS ADMINISTRATIVOS FORMALIZADOS Y PROCEDIMIENTOS ADMINISTRATIVOS NO FORMALIZADOS. IV. EL PROCEDIMIENTO ADMINISTRATIVO COMÚN, COMPETENCIA EXCLUSIVA DEL ESTADO, Y LOS PROCEDIMIENTOS REGULADOS POR LAS COMUNIDADES AUTÓNOMAS COMO INSTRUMENTALES DE LOS REGÍMENES SUSTANTIVOS DE COMPETENCIA DE LAS MISMAS. V. LAS NORMAS PROCEDIMENTALES DE LA LEY 30/1992.
\end{abstract}

\section{INTRODUCCIÓN}

La mayor parte de los estudios sobre la competencia estatal atinente al «procedimiento administrativo común» y sobre las competencias de las Comunidades Autónomas en el ámbito procedimental se han anclado en lo declarado por el Tribunal Constitucional hasta su Sentencia 227/1988, ésta incluida, por haberse publicado la casi totalidad de los mismos tras promulgarse la Ley 30/1992, de 26 de noviembre, de Régimen jurídico de las Administraciones públicas y Procedimiento Administrativo Común. Por ello, no encontramos en ellos las precisiones más recientes del propio Tribunal Constitucional sobre dichas competencias, las cuales deben ser resaltadas para llegar a una visión más completa y exacta de dicho asunto.

Pero, a su vez, tanto el análisis de aquella jurisprudencia y de la doctrina científica que se ha preocupado de las mismas, como de los más recientes fallos del TC, nos muestran que existen importantes sombras no sólo sobre la comprensión de su significado y alcance, sino también sobre la distinción entre procedimiento administrativo general y procedimientos administrativos especiales, especialmente por la mezcla que hace de tales cuestiones la citada STC 227/1988.

Y a ello se añade la incidencia de la dualidad procedimientos formalizados y procedimientos no formalizados, de la cual-como veremos- también se han pretendido sacar consecuencias en relación con el anterior problema. 
Sin embargo, una reflexión pausada de estas cuestiones, especialmente a la luz de las referidas resoluciones más recientes del TC y de las implicaciones del principio de especialidad normativa, creemos que permite aclarar las referidas incertidumbres, para lo cual resulta necesario, previamente, despejar el verdadero alcance de la distinción entre procedimientos administrativos generales y especiales, por un lado, y de procedimientos formalizados y no formalizados, por otro.

\section{PROCEDIMIENTOS ADMINISTRATIVOS GENERALES Y ESPECIALES}

En realidad responde a la distinción entre normas generales y normas especiales, pudiendo hablarse entonces de normas procedimentales generales y normas procedimentales especiales.

En este sentido, E. García de EnTERría y T.R. Fernández dicen que el Título VI de la Ley 30/1992 lo que contiene son «las disposiciones generales sobre los procedimientos administrativos $\rangle^{1}$.

Es decir, los procedimientos generales en realidad son normas generales de procedimiento que se aplican en defecto de normas especiales.

Así, por ejemplo, antes de que el reintegro de las subvenciones contara con normas procedimentales para el mismo (art. 8 del Real Decreto $2225 / 1993$, de 17 de diciembre), ante la ausencia de un procedimiento específico para ello, le eran aplicables las normas generales procedimentales correspondientes.

Un ejemplo de normas procedimentales especiales es el de las recogidas en la propia Ley 30/1992 (art. 134 a 138) y en su Reglamento del procedimiento para el ejercicio de la potestad sancionadora, aprobado por Real Decreto 1398/1993, de 4 de agosto², que, a su vez, actúan «como normas generales procedimentales en materia sancionadora» frente a las normas procedimentales sancionadoras en materia de tráfico del Real Decreto Legislativo 339/1990, de 2 de marzo, por el que se aprueba el

\footnotetext{
${ }^{1}$ E. García de Enterría y T.R. FernándeZ, «Curso de Derecho Administrativo», Tomo II, Ed. Thomson-Civitas. Madrid 2004, pp. 466-467 y 496.

2 Téngase en cuenta que ya la LPA de 1958 calificaba como procedimiento especial las normas de procedimiento sancionador recogidas en los arts. 133 y ss. de tal Ley. Como también calificaba como procedimientos especiales el de elaboración de los Reglamentos y el de las reclamaciones previas al ejercicio de las acciones civiles y laborales, incluidos los tres en el Título VI de dicha Ley, bajo la rúbrica «Procedimientos especiales».
} 
Texto Articulado de la Ley sobre tráfico, circulación de vehículos a motor y seguridad vial (art. 73 y ss.) y su Reglamento de procedimiento sancionador, aprobado por el Real Decreto 320/1994, de 25 de febrero.

La dualidad general-especial se plantea siempre entre dos normas, de modo que cabe que una norma especial B frente a una norma general A, sea a su vez general con respecto a una norma $\mathrm{C}^{3}$. Por eso, que las normas de los arts. 134 a 138 de la Ley 30/1992 y del RD 1398/1993 sean especiales frente a las del título VI de la Ley 30/1992 no les impiden a su vez ser generales frente a las normas procedimentales sancionadoras especiales en materia de tráfico.

Y otro ejemplo de normas procedimentales especiales recogidas en la propia Ley 30/1992 son las dedicadas al procedimiento para la sustanciación de los recursos administrativos del art. 110 y ss.; o al procedimiento para la sustanciación de las reclamaciones administrativas previas a la vía judicial civil o laboral del art. 122 y ss.; o al procedimiento para la revisión de oficio de los actos nulos de pleno derecho (arts. 102 y 104 de la Ley 30/1992); o a los procedimientos para la ejecución forzosa de los actos administrativos (arts. 96 y siguientes de la Ley 30/1992); o a los procedimientos para la exacción de responsabilidad patrimonial de las Administraciones Públicas (arts. 142 y 143 de la Ley 30/1992).

Y hay que recordar que, según el principio de especialidad normativa se aplicarán preferentemente las normas especiales sobre las generales y éstas en defecto de las especiales ${ }^{4}$. Y podemos añadir que las normas especiales pueden establecer soluciones distintas de las generales siempre que ello sea conforme con el derecho fundamental-principio de igualdad y con el resto de los derechos fundamentales ${ }^{5}$.

Sin embargo, tal solución distinta, si contradice las normas consideradas como de procedimiento administrativo común reguladas por la Ley 30/1992 (que unas son generales y otras especiales), no será posible en el caso de las normas procedimentales de las Comunidades Autónomas instrumentales de los regímenes sustantivos sobre los que éstas ya ostentan competencias, que el Tribunal Constitucional ha reconocido como competencia de las mismas, por lo que, en nuestra opinión, no es afortunada

\footnotetext{
${ }^{3}$ Sobre dicho principio y las relaciones entre normas especiales y generales, me remito a mí trabajo «El principio de especialidad normativa (lex specialis) y sus aplicaciones jurisprudenciales» $R A P$ 162, año 2003, p. 189 y ss. y, en especial sobre lo anterior, la p. 200.

${ }^{4}$ Ibidem, p. 193.

5 Ibidem, p. 197.
} 
la calificación que el propio TC hace de tales procedimientos autonómicos como especiales ratione materiae, en su Sentencia 227/1988, pues mezcla dos dualidades, en principio, distintas: la que enfrenta las normas generales a las especiales y la que contrapone las normas estatales de procedimiento administrativo común a las normas procedimentales citadas de las Comunidades Autónomas, que analizamos más adelante.

\section{PROCEDIMIENTOS ADMINISTRATIVOS FORMALIZADOS Y PROCEDIMIENTOS ADMINISTRATIVOS NO FORMALIZADOS}

Como destaca el profesor F. GonzÁlez NaVArro, Magistrado Ponente además de la STS de 12 de febrero de 1986 (RJ 1986\2156), en la que se recoge la distinción que ahora analizamos, procedimientos formalizados son aquellos en los que su tramitación aparece preestablecida por el Derecho Positivo y su orden ritual se prescribe en la norma, imponiéndose al instructor del procedimiento, que ve de esta manera cómo imperativamente se le marca el cauce que ha de seguir para el ejercicio de las potestades de que está dotada la Administración. Por contra, los procedimientos no formalizados son aquellos otros en los que se deja en libertad al instructor para fijar la tramitación como un arsenal de herramientas procesales a disposición de éste, que las utilizara según convenga en cada caso.

Este mismo Autor nos dice que la Ley de Procedimiento Administrativo de 1958 y la Ley 30/1992 no han regulado un procedimiento administrativo rígido, formalizado, en el sentido de que cada trámite tiene su causa en el que le precede y que, a su vez, es causa del que le sigue, de acuerdo con el principio de preclusión procesal, sino que se ha limitado a poner en poder del instructor o de las partes unos instrumentos (prueba, informe, audiencia, etc), de los que, según los casos, pueden o deben hacer uso, con vistas a la decisión que en su día haya de dictarse. De ahí que, en el Título IV de la Ley de Procedimiento Administrativo de 1958, se haya establecido un procedimiento no formalizado o flexible que se contrapone a otros procedimientos formalizados o rígidos, cuya tramitación escalonada se regula con carácter preclusivo, bien en la propia Ley de Procedimiento Administrativo (en el Título VI bajo la rúbrica «procedimientos especiales») o bien en otras normas legales o reglamentarias.

Añade que, como destacó la Exposición de Motivos de la LPA de 1958, «la Ley ha huido $[. .$.$] de la ordenación rígida y formalista de un procedi-$ miento unitario en el que se dan todas aquellas actuaciones integradas como fases del mismo y, en consecuencia, no regula la iniciación, orde- 
nación, instrucción, y terminación, como fases o elementos preceptivos del procedimiento, sino como tipo de actuaciones que podrán darse o no en cada caso, según la naturaleza y exigencias propias del procedimiento del que se trate».

Y culmina señalando que lo mismo puede decirse de las normas procedimentales reguladas en el Título VI de la Ley 30/1992, el denominado procedimiento general o normas procedimentales generales de la citada Ley, que no responden al esquema de un procedimiento escalonado con fases cuyas actuaciones además deban ser sucesivamente necesarias unas de otras y deban darse en todo caso. Por ejemplo, en cuanto al trámite de alegaciones, dice que los interesados pueden utilizarlo en cualquier momento del procedimiento anterior al trámite de audiencia, pero no impone un trámite de alegaciones específico, en un momento procedimental concreto. Los actos de instrucción los regula de un modo bastante amplio, sin ni siquiera exigir que el órgano encargado de tales actos, el instructor, deba ser necesariamente distinto del órgano competente para resolver. También regula de forma muy genérica la prueba, sin establecer un momento procedimental concreto de la misma y esto sucede igualmente con los informes y con el trámite de información pública, que no aparece como preceptivo en virtud de la propia Ley 30/1992, sino tan sólo cuando normas especiales así lo establezcan, de tal modo que en los demás casos va a depender de la decisión del órgano competente para dictar la resolución final del procedimiento, cuando la naturaleza de éste lo requiera. En cuanto al trámite de audiencia, tan sólo prescribe que deberá adoptarse cuando no figure en el procedimiento ni sean tenidos en cuenta en la resolución otros hechos ni otras alegaciones y pruebas que las aducidas por el interesado ${ }^{6}$.

A nuestro entender, debe admitirse que estamos ante un procedimiento menos formalizado y menos escalonado que el recogido por ejemplo en el Reglamento para el ejercicio de la potestad sancionadora aprobado por el Real Decreto 1328/1993, de 4 de agosto, que sí establece una secuencia ordenada y preclusiva de actuaciones a partir de su art. 11, y, en ese sentido, puede calificarse como flexible y no formalizado.

Efectivamente, incluye previsiones que dejan libertad a los interesados, como las alegaciones del art. 79 y la proposición de prueba, según se deri-

\footnotetext{
6 J. GonzÁlez Pérez-F. GonzÁlez NAVArro, «Comentarios a la Ley de Régimen jurídico de las Administraciones Públicas y del Procedimiento Administrativo Común», $3^{a}$ Edición, Ed. ThomsonCivitas, Madrid 2003 «Comentarios...», p. 96 y ss. F. GonZÁLeZ NAVARRo, «Derecho Administrativo Español». Tomo III: «El acto y el procedimiento administrativo». EUNSA. Pamplona 1997, p. 543 y ss.
} 
va del art. 81, o al órgano instructor, tales como la petición de informes no exigidos por el Ordenamiento Jurídico que se juzguen necesarios a los órganos administrativos para resolver con fundamentación de la conveniencia de reclamarlos (art. 82); la adopción de oficio de medidas provisionales que estime oportunas para asegurar la eficacia de la resolución que pudiere recaer (art. 72); los actos de instrucción en sentido estricto a realizar (art. 78); y los actos de prueba promovida de oficio (art. 81).

Sin embargo, también debe destacarse la presencia en dichas normas procedimentales de exigencias obligatorias tales como los requisitos de la instancia, en el procedimiento iniciado a solicitud del interesado del art. 70; el emplazamiento para subsanación de los defectos de la solicitud del art. 71; el impulso de oficio en todos los trámites, una vez iniciado el procedimiento (art. 74.1); la tramitación según orden riguroso de incoación, en asuntos de naturaleza homogénea, salvo orden motivada en contrario; la no suspensión del procedimiento por cuestiones incidentales salvo la recusación (art.77); la obligación del trámite de audiencia cuando figuren en el procedimiento o deban ser tenidos en cuenta en la resolución hechos, alegaciones y pruebas distintas de las aducidas por el interesado (art. 84.4, sensu contrario); y los recogidos en relación con las resoluciones finales, tales como la congruencia con las peticiones formuladas por los interesados y demás que allí se incluyen.

Y, en cuanto a la secuencia de actuaciones, también se incluyen prescripciones obligatorias. Por un lado, la clara distinción de tres fases dentro del procedimiento: la iniciación de oficio o previa solicitud del interesado (Capítulo I); la instrucción en sentido amplio (rúbrica de las actuaciones del Capítulo III del Título VI); y la finalización del mismo (Capítulo IV), ordinariamente mediante la resolución (art. 89). Y, por otro, dentro de la fase de instrucción en sentido amplio (rúbrica de las actuaciones del Capítulo III del Título VI), se prescribe que las alegaciones in genere deben formularse siempre antes del trámite de audiencia; que los actos de instrucción en sentido estricto y la prueba deben realizarse antes del trámite de audiencia; y que ésta debe efectuarse, una vez realizada la instrucción y la prueba y antes de la propuesta de resolución. Y, a su vez, puede interpretarse que del art. 84 se deriva la exigencia de propuesta de resolución anterior a la resolución, con separación de órgano de instrucción y órgano de resolución, aunque también cabe la interpretación de que la propuesta de resolución no es obligatoria con carácter general y que, sólo si la hubiere, el trámite de audiencia debe ser anterior a dicha propuesta ${ }^{7}$.

7 La STC 76/1990 (FJ 8, letra A) afirma en este sentido lo siguiente: «Por la naturaleza misma de los procedimientos administrativos, en ningún caso puede exigirse una separación entre instrucción 
Es decir, que las normas procedimentales del Título VI de la Ley 30/1992, aun sin establecer una secuencia de actuaciones tan cerrada como el referido RD 1398/1993, sí que dispone una secuencia mínima y una serie de prescripciones obligatorias que configuran una estructura procedimental mínima y una serie de previsiones preceptivas que deben darse cuando concurren las circunstancias previstas en la propia Ley. Lo que, a su vez, suministra un procedimiento que puede actuar como norma general, aplicable en defecto de norma especial, y de una estructura procedimental y de unas normas procedimentales mínimas, que junto con otras de la misma Ley (tales como las especiales para el ámbito sancionador recogidas en los arts. 134 y ss. y demás especiales recordadas atrás), son aplicables a todas las Administraciones públicas como procedimiento administrativo común.

Por eso, no cabe entender, desde nuestro punto de vista, que el hecho de que la Ley 30/1992 (como la anterior LPA) no regule un procedimiento totalmente formalizado, al estilo del RD. 1398/1993, ello habilite por sí mismo a las Comunidades Autónomas para establecer regulaciones procedimentales propias. Éstas deberán estar exclusivamente a sus títulos competenciales reconocidos al efecto en la propia Constitución (especialidades procedimentales derivadas de especialidades organizativas -art. 149.1.18-) o por la jurisprudencia constitucional (normas procedimentales instrumentales de los regímenes sustantivos sobre los que éstas ya ostentan competencias).

Nos apartamos así de la tesis mantenida por F. GonZÁlez NAVARRO y recogida en la STS de 6 de noviembre de 1986 (RJ 198617815, FJ. $3^{\circ}$ ), de la que él mismo fue Ponente, según la cual las Comunidades Autónomas están habilitadas para crear cauces procesales inéditos cuando el procedimiento adecuado a una concreta actividad administrativa no esté formalizado.

\footnotetext{
y resolución equivalente a la que respecto de los Jueces ha de darse en los procesos jurisdiccionales». Aunque del contexto del resto de la Sentencia se infiere que ello depende de lo que disponga el legislador, que, en relación con el procedimiento administrativo, puede separarlas o asignárselas a un mismo órgano, como ocurre con las funciones de inspección y liquidación tributaria.

Pero también hay que tener en cuenta que, en la misma Sentencia, se alude a la STS de 24 de abril de 1984 (RJ 1984\2711, Cdos. 6 y 10, que afirmó, obiter dicta, que la distribución legal de funciones inspectoras y liquidadoras configuraba garantías procedimentales para los contribuyentes que no podían quedar a la libre discrecionalidad de la potestad organizadora de la Administración, «salvo que por otra disposición con rango de Ley se alteren aquellos principios que, como de orden público, y hasta que esto último no suceda, han de ser respetados».
} 


\section{EL PROCEDIMIENTO ADMINISTRATIVO COMÚN, COMPETENCIA EXCLUSIVA DEL ESTADO, Y LOS PROCEDIMIENTOS REGULADOS POR LAS COMUNIDADES AUTÓNOMAS COMO INSTRUMENTALES DE LOS REGÍMENES SUSTANTIVOS DE COMPETENCIA DE LAS MISMAS}

El art. 149.1.18 atribuye al Estado la competencia exclusiva, por un lado, sobre «las bases del régimen jurídico de las Administraciones públicas y del régimen estatutario de sus funcionarios que, en todo caso, garantizarán a los administrados un tratamiento común». Pero, por otro lado, con un punto y coma respecto a lo anterior, atribuye también al Estado competencia exclusiva sobre el «procedimiento administrativo común, sin perjuicio de las especialidades derivadas de la organización propia de las Comunidades Autónomas»».

1. En primer lugar, es incontrovertido que la Constitución, en relación con las normas estatales sobre procedimiento administrativo común, reconoce la aplicación de las especialidades derivadas de la organización propia de las Comunidades Autónomas.

La STC 76/1983 (F.J. 23) declara que «tales especialidades deberán ser aprobadas por Ley de la respectiva Comunidad Autónoma, sin que en ningún caso puedan reducirse las garantías que establece la legislación en favor del administrado».

Y, por eso, la STC 204/1992, FJ. 5º en la misma línea, admite que, en el procedimiento para la elaboración de los Reglamentos ejecutivos, dictamine un órgano administrativo consultivo distinto del Consejo de Estado, creado por la correspondiente Comunidad Autónoma, siempre que esté dotado de las características de organización y funcionamiento que aseguren su independencia, objetividad y rigurosa cualificación técnica. Pero, si tal Comunidad no cuenta con un órgano de tales características, entonces las garantías procedimentales exigen mantener la intervención preceptiva del Consejo de Estado, en tanto que órgano al servicio de la concepción global de Estado que la Constitución establece.

Tal Sentencia califica expresamente la sustitución del Consejo de Estado por el órgano consultivo autonómico como «especialidad derivada de su organización propia»; exige que tal órgano cuente con las características citadas para que no se produzca una reducción de garantías procedimentales; y afirma que ello rige en todos los casos que formen parte de las 
bases del régimen jurídico de las Administraciones públicas o del procedimiento administrativo común, circunstancia que concurre en el caso de la elaboración de los reglamentos para la ejecución de las leyes (FJ. $\left.6^{\circ}\right)^{8}$.

Otro ejemplo de lo anterior es la intervención en el procedimiento de revisión de oficio de los actos administrativos nulos de pleno derecho, en lugar del Consejo de Estado, del órgano consultivo equivalente a éste creado en las correspondientes Comunidades Autónomas, que cuente con las características arriba citadas. Tal sustitución podía mantenerse como aplicación del citado inciso del art. 149.1.18 de la Constitución Española, aún bajo la vigencia de la Ley de Procedimiento Administrativo de 1958, que tan sólo mencionaba al Consejo de Estado y, claramente hoy, no sólo por tal previsión constitucional, sino también por contemplarlo expresamente la Ley 30/1992, en su art. 102.1.

2. Por otro lado, es patente que nos encontramos ante la atribución de competencia normativa al Estado para establecer unas normas procedimentales aplicables a todas las Administraciones Públicas, incluidas las de las Comunidades Autónomas. Eso nadie lo discute. Se colige del adjetivo «común».

El problema estriba en si tal atribución incluye toda la normativa sobre procedimiento administrativo o sólo una parte de la misma, es decir si se configura como una competencia de legislación plena o como una competencia de legislación compartida. Y, en este último caso, qué competencias concretas pueden ostentar las Comunidades Autónomas.

Hasta ahora, se han mantenido fundamentalmente dos interpretaciones: su consideración como competencia de legislación plena y su entendimiento como legislación básica estatal. Aunque -como veremos- la jurisprudencia constitucional no conduce exactamente ni a lo uno ni a lo otro.

\footnotetext{
${ }^{8}$ Hay que destacar que la vinculación aquí de este trámite-garantía en el procedimiento de elaboración de reglamentos con la competencia estatal de procedimiento administrativo común contrasta con la afirmación por el propio TC, en su Sentencia anterior 15/1989, de que tal procedimiento no formaba parte de tal competencia estatal. Esa es quizá la razón por la que haga ahora la referencia indistinta a dicha competencia y a la competencia estatal para aprobar las bases sobre régimen jurídico de las Administraciones públicas.

Pero, en cualquier caso, nos parece una rectificación del TC con respecto al criterio mantenido en la sentencia anterior, en la línea defendida por autores tales como F. LóPEZ MENUDO («Los principios generales del procedimiento administrativo». RAP 129, año 1992, p. 70) y J. ToRNOS MÁs («Título competencial del Estado, ámbito de aplicación y entrada en vigor», en el libro colectivo coordinado por él mismo: «Administración pública y procedimiento administrativo. Comentarios a la Ley 30/1992». Ed. Bosch. Barcelona 1994, p. 42), que consideran que no es correcta la doctrina a este respecto de la STC 15/1989. Concretamente, F. LÓPEZ MENUDO, porque el procedimiento reglamentario «contempla garantías que traducen principios constitucionales de información y participación ciudadana pertenecientes de iure al procedimiento administrativo común que corresponde asegurar al Estado».
} 
La tesis de su consideración como competencia de legislación plena ha sido defendida, en un primer momento, por autores tales como F. SAINZ Moreno, J.L. Piñar Mañas y E. GarCía De ENTERRía y, nominalmente, en parte, por la Exposición de Motivos de la Ley 30/1992.

J.L. PIÑar MAÑas consideró tempranamente que estábamos ante una legislación no sólo de aspectos básicos, sino también de aspectos concretos, al destacar que, si el constituyente hubiera querido atribuir al Estado solamente la legislación básica respecto al procedimiento administrativo, la Constitución no hubiera previsto la atribución a éste de competencia exclusiva sobre el procedimiento administrativo común de forma diferenciada con respecto al «régimen jurídico de las Administraciones públicas» respecto al cual únicamente le confiere la legislación básica.

Pero, además, sostiene este Autor que al Estado le corresponden también las bases del procedimiento administrativo no común, como parte de su competencia para aprobar las bases del régimen jurídico de las Administraciones públicas que le confiere el art. 149.1.18 CE. Y las Comunidades Autónomas pueden ostentar competencia no sólo sobre la regulación de las especialidades del procedimiento administrativo común derivadas de su propia organización, sino también sobre el desarrollo normativo de las bases estatales reguladoras del procedimiento administrativo no común?

F. SAINZ Moreno ha subrayado que la regulación estatal derivada del 149.1.18 es plena y no básica, porque no reconoce desarrollo normativo a las Comunidades Autónomas ${ }^{10}$.

9 J.L. PIÑAR MAÑAS, «Procedimiento administrativo y Comunidades Autónomas», en la obra colectiva «Gobierno y Administración en la Constitución», de la Dirección General del servicio Jurídico del Estado, publicada por el Instituto de Estudios Fiscales. Madrid 1988, Volumen II, pp. 1448 y ss., en especial, pp. 1460-1461.

${ }^{10}$ F. SAINZ Moreno, «La responsabilidad patrimonial de las Administraciones públicas en la Ley de régimen Jurídico y de Procedimiento Administrativo Común. Especial referencia a la responsabilidad por no ejercicio de sus competencias», en «Estudios sobre la nueva Ley de régimen Jurídico y de Procedimiento Administrativo Común (seminario de Derecho Local, curso 1992-1993), Ayuntamiento de Barcelona. Barcelona 1992, pp. 78 y ss.

Ahora bien, en un trabajo posterior, afirma que, a partir de la STC 227/1988, que reconoce a las Comunidades Autónomas la regulación de normas procedimentales instrumentales de sus regímenes sustantivos propios, la distinción entre competencia sobre procedimiento administrativo común y sobre régimen jurídico de las Administraciones públicas «ha quedado muy desdibujada» y el planteamiento de la cuestión ha cambiado radicalmente («Principios y ámbito de aplicación de la $L A P$, en particular, artículos 1 a 3 », incluido en el libro colectivo «Administraciones públicas y ciudadanos -Estudio sistemático de la Ley 30/1992...-», coordinado por B. PENDÁs García. Ed. Praxis. Madrid 1993, p. 161-165). Y, en otro estudio ulterior, reitera tal ensombrecimiento e indica que «no 
Y E. GARCíA DE ENTERRÍA ha destacado que la regulación del procedimiento administrativo común no es una «simple competencia de regulación básica, sino de regulación total o integral. La única competencia que en materia de procedimiento administrativo se reserva a las Comunidades Autónomas es la relativa a «las especialidades» (que es otra cosa que un «procedimiento específico») derivadas de su organización propia, precisamente, y nada más». Por ello, ha recalcado que el reconocimiento que hace el artículo 1 del RD 1398/1993, que aprueba el Reglamento de procedimiento para el ejercicio de la potestad sancionadora, de que en materia de procedimiento administrativo tienen competencias propias las Administraciones de las Comunidades Autónomas y las entidades que integran la Administración Local ni está en la Ley 30/1992, ni al propio Legislador se lo permitiría siquiera la Constitución. Y afirma que «el procedimiento administrativo (y el aplicable al ejercicio de la potestad sancionadora lo es, indudablemente, art. 134 de la Ley 30/1992) ha de ser común, y regularlo en ese ordenamiento común es una competencia exclusiva del Estado», precisando que «la competencia regulativa del Estado no es aquí la de meros principios o bases, sino integral, de modo que la observancia de los mismos no puede abrir la puerta a otras competencias normativas de desarrollo» ${ }^{11}$.

La Exposición de Motivos de la Ley 30/1992 (Epígrafe 2) consigna expresamente que, a diferencia de la regulación del régimen jurídico de las Administraciones Públicas, en el que se confiere al Estado sólo las bases, que gira sobre el esquema «bases más desarrollo», en el supuesto del «procedimiento administrativo común», la CE atribuye al Estado una competencia normativa plena y exclusiva del Estado. Pero, a continuación, afirma que tal regulación procedimental no excluye las competencias ya sea de las Comunidades ya sea del Estado para regular procedimientos específicos «ratione materiae», con invocación de la jurisprudencia constitucional que admite competencias de las Comunidades Autónomas para dictar normas de procedimiento necesarias para la aplicación de su derecho sustantivo (claramente la STC 227/1988) y, así, puede hablarse de regulación de procedimientos propios de las Comunidades Autónomas que debe respetar la competencia reguladora del Procedimiento Administrativo Común.

parece posible precisar qué alcance práctico tiene para el Estado y para las Comunidades Autónomas la referida distinción (Voz «Procedimiento Administrativo Común», en Enciclopedia Jurídica Básica de Editorial Civitas, Madrid 1995, pp. 5160-5161).

${ }^{11}$ E. GARCÍA DE ENTERRÍA: «La problemática puesta en aplicación de la LRJ-PAC: el caso del Real Decreto 1398/1993, de 4 de agosto, que aprueba el Reglamento del procedimiento para el ejercicio de la potestad sancionadora. Nulidad radical del Reglamento y desintegración general del nuevo sistema legal». REDA 80, año 1993 (epígrafe III). 
Tienen razón J. GonzÁLez Pérez-F. GonZÁlez NAVARro cuando mantienen que aquí la Exposición de Motivos se contradice ${ }^{12}$. Porque si indica que a las Comunidades Autónomas se le reconocen competencias normativas en materia de procedimiento, la competencia del Estado sobre normas procedimentales no sería plena, sino compartida.

Y la tesis según la cual estamos ante una manifestación de legislación estatal básica es defendida por autores tales como F. LóPEZ MenUdo; F. López Ramón; J. Tornos Más; y J. GonzÁlez Pérez y F. GonzÁlez NaVARRO.

F. López MENUdo sostiene que las normas de procedimiento administrativo común deben regular a) aquello que constituye las condiciones básicas garantizadoras de un tratamiento igual a todos los españoles y b) la unificación de las instituciones directamente enlazadas con la seguridad jurídica ${ }^{13}$. Es decir, toda cuestión verdaderamente nuclear ${ }^{14}$, lo que se traduce en la exigencia de que se centre en los principios generales del procedimiento y en diversos institutos procedimentales que aparecen transidos de aquéllos, excluyendo las simples reglas y las meras soluciones técnicas de carácter contingente ${ }^{15}$. Y afirma que tal conclusión es en realidad la misma que el TC predica de las leyes básicas ${ }^{16}$.

Y F. LÓPEZ RAMÓN se manifiesta en igual sentido. La finalidad de las normas de procedimiento administrativo común es la certeza de los particulares de que todas las Administraciones a las que se dirijan van a actuar con criterios homogéneos (como recoge el epígrafe 4 de la Exposición de Motivos de la Ley 30/1992) y que existan unas garantías procedimentales comunes en todo el Estado ${ }^{17}$. Y afirma que, en realidad, tal competencia debería ser caracterizada como una competencia sobre las bases del procedimiento ${ }^{18}$.

J. ToRnos MÁs afirma en la misma línea que «bases del régimen jurídico y procedimiento administrativo se identifican, de hecho, material y

\footnotetext{
12 J. GonzÁlez PÉrez-F. GonZÁlez Navarro, «Comentarios...», p. 127.

13 F. LóPEZ MENUdo, «Los principios generales del procedimiento administrativo». RAP 129, año 1992, pp. 74-75.

14 Ibidem, p. 74.

15 Ibidem, p. 76.

16 Ibidem, p. 74.

17 F. LÓPEz RAMÓN, «Reflexiones sobre el ámbito de aplicación de la Ley de Régimen jurídico de las Administraciones públicas y del procedimiento común». RAP 130, año 1993, p. 108.

18 Ibidem, p. 110.
} 
funcionalmente». «Dentro del concepto material régimen jurídico cabe incluir la materia procedimiento administrativo, en tanto que regulación del régimen de producción de actos» y, por otro lado, «el adjetivo común, al predicarse del procedimiento administrativo, convierte la competencia legislativa estatal en competencia funcionalmente básica». Y considera apoyada tal tesis en algunas sentencias del TC (como la 204/1992) que invocan indistintamente ambos títulos competenciales ${ }^{19}$.

Y J. González Pérez y F. González Navarro destacan, por un lado, que, según la Sentencia del Tribunal Constitucional 227/1988, estamos ante competencia compartida con las Comunidad Autónomas. Y añaden, por otro, que el procedimiento administrativo es una parte del régimen jurídico de las Administraciones Publicas, lo que se confirma porque el Tribunal Constitucional en la Sentencia 227/1988 contempla dentro de la competencia sobre procedimiento administrativo común, de modo conjunto, no sólo aspectos estrictamente procedimentales (tramitación estricta dicen los Autores), sino también aspectos del régimen jurídico de las Administraciones Públicas no estrictamente procedimentales, como los requisitos de validez y eficacia de los actos, los modos de revisión de los mismos y los medios de ejecución de éstos. Y, si la competencia del Estado sobre el citado régimen jurídico es la propia de la legislación básica, ésta es la que corresponde igualmente sobre la regulación procedimental ${ }^{20}$.

En tono crítico a lo anterior, S. MARTín Retortillo afirmaba que la interpretación que incluye el procedimiento administrativo común dentro de la competencia sobre el régimen jurídico de las Administraciones públicas no parecía correcta, por cuanto ha sido identificada en su singularidad por el art. 149.1.18 CE. Y demostró cómo la enmienda del Grupo Vasco que intentó circunscribir la competencia estatal a las bases fue rechazada. Si bien, añadía que ésta sería la interpretación que terminaría por generalizarse, con notable ampliación de las competencias de las Comunidades Autónomas ${ }^{21}$, en virtud de la evidente desviación interpretativa que ha llevado a cabo el TC a partir de la equívoca exégesis de un párrafo de la STC 76/1983.

\footnotetext{
19 J. ToRnOs MÁs, «Título competencial del Estado, ámbito de aplicación y entrada en vigor», en el libro colectivo coordinado por él mismo: «Administración pública y procedimiento administrativo. Comentarios a la Ley 30/1992». Ed. Bosch. Barcelona 1994, p. 40 y ss.

20 J. González Pérez y F. GonzÁlez Navarro, Comentarios, pp. 125 a 131. El propio Tribunal Constitucional ha dicho que el procedimiento y el régimen de recursos forman parte, entre otros aspectos, de la expresión «régimen jurídico de las administraciones públicas» (STC 76/1983, FJ. 38).

${ }^{21}$ S. MarTín Retortillo, «Reflexiones sobre el procedimiento administrativo común». RAP 131, año 1993, pp. 8-9.
} 
En esta Sentencia afirma el citado intérprete constitucional la constitucionalidad de los preceptos de los Estatutos Vasco y Catalán en los que se hace referencia conjunta tanto a las especialidades organizativas como a las especialidades derivadas del Derecho sustantivo como competencia propia de las respectivas Comunidades, porque en tales preceptos se recogen indiferenciadamente tanto la competencia del art. 149.1.6 sobre legislación procesal («sin perjuicio de las necesarias especialidades que en este orden se deriven del derecho sustantivo de las Comunidades Autónomas»), como la competencia del art. 149.1.18 sobre procedimiento administrativo común («sin perjuicio de las especialidades derivadas de la organización propia de las Comunidades Autónomas»). Y, aunque parece clara tal distinción en la Sentencia citada, después la misma no se sigue por el propio $\mathrm{TC}^{22}$, que, a partir de su Sentencia 227/1988, reconocerá a las Comunidades Autónomas competencias para establecer regulaciones procedimentales que recojan especialidades vinculadas al Derecho sustantivo sobre cuya regulación ostentan competencias.

3. Y, por nuestra parte, debemos destacar, en primer término, en la línea resaltada por S. MARTín RETORTILLO, que, aunque sea verdad que el procedimiento administrativo pueda considerarse una parte del régimen jurídico de las Administraciones Públicas, lo que está claro es que el poder constituyente español ha separado el género (régimen jurídico) y la especie (procedimiento administrativo) mediante un punto y coma, con la finalidad clara de establecer dos títulos competenciales diferenciados. Puede decirse, además, que para la especie (el procedimiento administrativo) ha establecido una norma competencial especial frente a la norma competencial del género (el régimen jurídico de las Administraciones Públicas), que, como toda norma general tan sólo se aplica en defecto de norma especial.

Y el mismo Tribunal Constitucional ha dejado sentado con carácter general que la inclusión de una competencia genérica debe ceder ante la competencia específica (SSTC 71/1982; FJ 2º 87/1989; 133/1997, FJ 13; y $186 / 1999, \mathrm{FJ}^{\circ}$ ).

En la STC 50/1999, FJ $3^{\circ}$, se indica que hay aspectos en los que se aplicará la competencia específica de «procedimiento administrativo común» y otros en los que regirá la competencia genérica, al declarar que no toda regulación que incida en el procedimiento entendido en el sentido amplio fijado por el Tribunal Constitucional a partir de la STC 227/1988 (que hemos estudiado atrás) forma parte del título competencial «procedimien-

22 Ibidem, pp. 12-13. 
to administrativo común», de modo que no es reconducible al mismo la regulación que tan sólo de forma indirecta tiene repercusión o incidencia en el mismo ampliamente entendido o cuyo incumplimiento puede tener como consecuencia la invalidez del acto, pues esto obedece al título competencial sobre «régimen jurídico de las Administraciones Públicas».

Pero, por otro lado, debemos recordar que, si al Estado se le reconociese tan sólo la competencia para aprobar la legislación básica sobre las normas procedimentales, a las Comunidades Autónomas le correspondería la legislación de desarrollo. Y, a estos efectos, debemos tener en cuenta que la dualidad legislación básica del Estado-legislación de desarrollo de las Comunidades Autónomas ha sido interpretada por el Tribunal Constitucional fundamentalmente de los siguientes modos: a) al Estado le corresponde la regulación de los principios o criterios básicos, (STC 32/1981, FJ. $5^{\circ}$ ), de lo que se colige que las Comunidades Autónomas pueden asumir competencias sobre una normativa que desarrolle esos principios o criterios básicos; b) que al Estado le corresponde una regulación de mínimos, pudiendo establecer las Comunidades Autónomas requisitos adicionales de los mínimos señalados por la normativa estatal ${ }^{23}$; c) al Estado le corresponde una regulación que asegure de manera unitaria y en condiciones de igualdad los intereses generales sobre una materia y a las Comunidades Autónomas una regulación de dicha materia que establezca las peculiaridades relacionadas con sus propios intereses con respeto a la regulación estatal citada y dentro de las competencias que sobre dicha materia le asigne su Estatuto de Autonomía ${ }^{24}$; y d) que al Estado le corresponde la regulación de los «aspectos centrales, nucleares del régimen jurídico de una determinada institución» (STC 76/1986, FJ. $4^{\circ}$ y 103/1997, FJ.4º).

Sin embargo, lo que ha dicho el Tribunal Constitucional, con referencia a la competencia estatal sobre procedimiento administrativo común, en sus Sentencias 227/1988, FJ 32, y 98/2001, FJ 8, por un lado, y ha preci-

\footnotetext{
23 Así ha interpretado el Tribunal Constitucional la competencia del Estado sobre «bases y coordinación general de la sanidad» del art. 149.1.16 (SSTC 32/1983; 42/1983 y 80/1984) y las competencias estatales y autonómicas en relación con la protección del medio ambiente (SSTC 170/1989; 102/1995; 156/1995; 15/1998 y 306/2000). Véase en nuestro trabajo: «Instalaciones de telefonía móvil, salud y medio ambiente». Revista Aranzadi de Derecho ambiental n. ${ }^{\circ} 3$; año 2003, pp. 57-58.

${ }^{24}$ STC 248/1998 y las que allí cita. Este criterio viene a coincidir con la explicación de E. GARCÍA DE ENTERRÍA y T.R. FERNÁNDEZ, que subrayan que la dualidad legislación básica estatal-legislación de desarrollo de las Comunidades Autónomas no gira en torno al par principios-desarrollo de esos principios, ni sobre el par regulación abstracta o genérica y precisión concreta, sino sobre el de regulación por el Estado de todo aquello que sobre una materia afecte al interés general, incluso si el interés general exige una regulación pormenorizada, de detalle y exhaustiva, como recoge la STC 96/1996, de 30 de mayo (Ibidem, T. I, edición 2004, p. 304), en su FJ. 20.
} 
sado en las Sentencias 186/1999; 190/2000; 126/2002, FJ 10, letra a; y $75 / 2003$, por otro, es lo siguiente.

A la competencia estatal sobre procedimiento administrativo común del art. 149.1.18 CE. le corresponde la determinación de los siguientes principios o normas ${ }^{25}$ : a) por un lado, de la estructura general del iter procedimental que ha de seguirse para la realización de la actividad jurídica de la Administración y b) por otro, los que prescriben la forma de elaboración, los requisitos de validez y eficacia, los modos de revisión de los actos administrativos y los medios de ejecución de los mismos; incluyendo señaladamente las garantías generales de los particulares en el seno del procedimiento (STC 227/1988, FJ 32; 98/2001, FJ 8; y 175/2003, FJ 10.c); pero no le pertenecen las «normas ordinarias de tramitación» que pueden dictar las Comunidades Autónomas en relación con los procedimientos relativos a las competencias que ostentan las Comunidades Autónomas para la regulación del régimen sustantivo de ciertas actividades o servicios (a partir de STC 186/1999, también en SSTC 190/2000; 126/2002 y 175/2003).

Por consiguiente, consideramos que la atribución de competencias que encierra la reserva al Estado del procedimiento administrativo común, al criterio que mejor se acomoda de los mencionados como caracterizadores de la legislación básica estatal según la jurisprudencia constitucional es a aquel que reconoce al Estado la regulación de los aspectos centrales, nucleares, de una institución y a las Comunidades Autónomas la regulación de los demás aspectos (es decir de los que no son centrales o nucleares).

En ese sentido, se aproxima a un modo de entender la legislación básica frente a la legislación de desarrollo que ha manejado el Tribunal Constitucional.

Pero, si estuviésemos ante legislación básica estatal, las Comunidades Autónomas, mediante una legislación de desarrollo, podrían regular los aspectos no centrales o nucleares del procedimiento como institución, en cualquier caso, cualquiera que fuera el régimen jurídico sustantivo del que dicho procedimiento es instrumental y ya fuera o no de su competencia la regulación de ese régimen jurídico sustantivo. Y ya hemos visto que el Tribunal Constitucional precisa que las normas procedimentales de las Comunidades Autónomas (aunque sean

\footnotetext{
25 Podemos hablar mejor de normas principiales y normas-regla, siguiendo la terminología de $\mathrm{M}$. AtienZa y J. Ruiz Manero en «Las piezas del Derecho». Ed. Ariel. Barcelona 1996.
} 
sobre aspectos no esenciales, no centrales, no nucleares, es decir, aunque sean «normas ordinarias de tramitación», según terminología del Tribunal Constitucional) tan sólo pueden versar sobre procedimientos instrumentales de los regímenes sustantivos sobre los que han asumido competencias, no sobre todos los procedimientos, ni sobre el procedimiento como institución (concluimos nosotros). Aquí está la diferencia.

Y, por consiguiente, las «normas ordinarias de tramitación» (aspectos procedimentales no centrales o nucleares) de procedimientos instrumentales (aspectos procedimentales de regímenes sustantivos) que corresponden al Estado también son competencia del Estado y no de las Comunidades Autónomas.

Por eso, a nuestro entender, no podemos identificar el significado de la competencia estatal sobre «procedimiento administrativo común» con el de la competencia estatal sobre legislación básica, aunque se aproxime en parte al mismo. Estamos ante un tipo de título competencial próximo al de la legislación básica, pero distinto de éste, como también es diferente del título «legislación plena», lo que determina que, según la interpretación que del mismo ha hecho el Tribunal Constitucional, en el caso que nos ocupa nos encontraremos, finalmente, ante competencias normativas compartidas ${ }^{26}$.

En suma, al Estado le corresponde, por el título competencial «procedimiento administrativo común», la regulación de los aspectos centrales o nucleares del procedimiento administrativo como institución, y por ello, de todos los procedimientos administrativos (ya sean generales o especiales), lo que según el Tribunal Constitucional incluye, entre otros apartados ya mencionados, la estructura general del procedimiento y las garantías generales de los particulares en el seno del mismo (sentencias mencionadas). Y, además, por el título competencial derivado de ser la regulación de los aspectos no nucleares del procedimiento una competencia conexa a la regulación de los regímenes sustantivos de actividades o servicios, también pertenece al Estado la normativa sobre los citados aspectos no nucleares («normas ordinarias de tramitación») de los procedimientos que son instrumentales de los regímenes sustantivos de competencia estatal.

Y las Comunidades Autónomas pueden asumir, por el último título competencial citado, la regulación de los aspectos no nucleares o centra-

\footnotetext{
${ }^{26}$ Entendemos que ésta es la conclusión a la que se llega en virtud de la jurisprudencia constitucional sobre dicho título competencial, aunque consideramos, en la línea apuntada por E. GARCíA DE ENTERRÍA y S. MARTíN-RetortiLlo, atrás expuesta, que aquí el Tribunal Constitucional se ha extralimitado y generado títulos competenciales para las Comunidades Autónomas que no están en la Constitución, ni en los Estatutos, interpretados conforme a la Constitución.
} 
les («normas ordinarias de tramitación»), únicamente de aquellos procedimientos instrumentales de los regímenes sustantivos de actividades o servicios sobre los que las mismas han asumido competencias. Y, por otro lado, en virtud del 149.1.18 de la Constitución Española (inciso «sin perjuicio de las especialidades derivadas de su organización»), pueden regular la incidencia de sus peculiaridades organizativas en la normativa sobre aspectos nucleares de los procedimientos administrativos que pertenece al Estado como «procedimiento administrativo común».

Otra cosa ocurre con la regulación que tan sólo de forma indirecta tiene repercusión o incidencia en el procedimiento ampliamente entendido (con los aspectos señalados por el TC a partir de la STC 227/1988) o cuyo incumplimiento puede tener como consecuencia la invalidez del acto, pues esto corresponde, según la STC 50/1999, FJ $3^{\circ}$, al título competencial sobre «régimen jurídico de las Administraciones Públicas» y, por ello, al Estado le pertenecerá la legislación básica y a las Comunidades Autónomas que la hayan asumido la legislación de desarrollo.

4. A su vez, las normas procedimentales de las Comunidades Autónomas, aprobadas, en virtud de sus especialidades organizativas, o en virtud de su competencia sobre procedimientos instrumentales de sus regímenes jurídicos sustantivos, sólo podrán complementar en esos ámbitos las normas de procedimiento común (la STC 17/1990, FJ. 11, habla de añadir reglas), pero no excluir garantías, tales como la audiencia al interesado en el trámite de adopción de medidas provisionales en un procedimiento tributario (STC 14/1986, FJ. 14) o como la exigencia de dictamen preceptivo de un órgano que posea las características del Consejo de Estado (STC 204/1992), ni reducir las garantías in genere (STC 76/1983, FJ. 23, que afirma la constitucionalidad del art. 18.1 del Proyecto de Ley Orgánica de Armonización del Proceso Autonómico, que excluye que las Comunidades Autónomas puedan a través de sus especialidades organizativas reducir las garantías establecidas por la legislación estatal en favor del administrado, que hoy se ha convertido en el art. 12.1 de la Ley 12/1983).

Y, si lo que se admite es añadir y no restar, hay que tener en cuenta, también, como destaca la STC 87/1985 (FJ 8, párrafo quinto), en relación con las normas sancionadoras y las garantías constitucionales dispuestas en este ámbito, que las Comunidades Autónomas no pueden introducir divergencias irrazonables y desproporcionadas al fin perseguido respecto del régimen jurídico aplicable en otras partes del territorio, por mor del art. 149.1.1 CE (es competencia exclusiva del Estado «la regulación de las condiciones básicas que garanticen la igualdad de todos los españoles en el ejercicio de los derechos y en el cumplimiento de los deberes constitucionales»)). 
Como, asimismo, debe recordarse, que, en relación con la competencia de las Comunidades Autónomas concerniente a la legislación procesal para establecer «las necesarias especialidades que en el orden procesal se deriven de las particularidades de su derecho sustantivo», que les posibilita el art. 149.1.6 CE, de cuya interacción con el art. 149.1.18 el TC ha ampliado las competencias sobre procedimiento administrativo de las Comunidades Autónomas (como ha explicado S. MARTín-RetortiLLO ${ }^{27}$ ), el TC ha declarado, en su Sentencia 83/1986, FJ 2, que «como indica la expresión «necesarias especialidades», se tienen en cuenta tan sólo las que inevitablemente se deduzcan, desde el punto de vista de la defensa judicial, de las reclamaciones jurídicas sustantivas configuradas por la norma autonómica en virtud de las particularidades del derecho creado por ellas».

5. Y en este punto hay que advertir que la terminología utilizada por el Tribunal Constitucional a partir de la Sentencia del Tribunal Constitucional 227/1988 en las Sentencias citadas, en la que contrapone «procedimiento administrativo común» como competencia estatal y «procedimientos administrativos especiales»o «normas procedimentales especiales ratione materiae» como competencia de las Comunidades Autónomas es no sólo confusa, sino errónea.

Procedimiento administrativo común o normas sobre los aspectos centrales de los procedimientos administrativos no se contraponen a procedimientos especiales o normas especiales de procedimiento ratione materiae, sino -como han aclarado las Sentencias del Tribunal Constitucional citadas posteriores a la 227/1988- a normas procedimentales no centrales («normas ordinarias de tramitación»), en relación exclusivamente con los procedimientos instrumentales de regímenes sustantivos competencia de cada Comunidad Autónoma en concreto, a las que podríamos denominar «normas procedimentales no comunes».

Como ha destacado S. Martín Retortillo, las normas de procedimiento administrativo común no se conciben para aplicarse en defecto de las normas de las Comunidades Autónomas, sino como directamente aplicables, por incluir las cuestiones nucleares que garantizan una igualdad básica de $\operatorname{trato}^{28}$.

Y, en la misma línea, L. PARejo Alfonso ha subrayado que lo común no es lo contrario a especial, sino a particular. Luego la perspectiva de la

27 Ob. cit., p. 12 y ss.

28 S. MARTín Retortillo, «Reflexiones ...», p. 26. 
relación de las normas procedimentales autonómicas con las estatales de procedimiento administrativo común no es la propia de la dicotomía procedimiento administrativo general y procedimientos administrativos especiales. Las normas de procedimiento administrativo común tienen como función la de garantizar la unidad de fondo, un mínimo común, y esto vincula a todos los ordenamientos territoriales (despliegue vertical) como a las normas especiales dentro de un mismo ordenamiento (despliegue horizontal $)^{29}$. Ya veremos, más adelante, en qué se traduce esto.

Hemos de recordar, por nuestra parte, que, según el principio de especialidad normativa, las normas procedimentales especiales tan sólo se contraponen a las normas procedimentales generales, según los criterios de diferenciación siguientes: las normas procedimentales generales son normas que regulan géneros de supuestos y actúan por defecto para el caso de que no existan normas procedimentales especiales aplicables, que son normas procedimentales reguladoras de especies concretas de un género, para supuestos definidos por el Ordenamiento Jurídico, y de aplicación preferente a las normas generales, que en el supuesto en cuestión quedan desplazadas ${ }^{30}$.

Y la supuesta contraposición entre norma de procedimiento administrativo común, como equivalente a norma general, y norma especial entra en contradicción con lo anterior, es decir con lo que el principio de especialidad normativa comporta. Por eso, la STC 17/1990 dice, en su FJ. 11, que las normas procedimentales de las Comunidades Autónomas pueden añadir reglas; lo que parece excluir que puedan sustituir las normas de procedimiento común.

Y, además, podemos encontrarnos con normas procedimentales especiales que no son competencia de las Comunidades Autónomas, sino de competencia estatal e incluso estatales de procedimiento administrativo común, tales como las normas procedimentales especiales para el ejercicio de la potestad sancionadora de las Administraciones Públicas (arts. 134 a 138 de la Ley 30/1992) $)^{31}$, o para la sustanciación de los recursos

\footnotetext{
${ }^{29}$ L. Parejo Alfonso, «Objeto, ámbito de aplicación y principios generales de la Ley de Régimen jurídico de las Administraciones públicas y del procedimiento común», en la obra colectiva «La nueva Ley de Régimen jurídico de las Administraciones públicas y del procedimiento común», dirigida por J. Leguina Villa y M. SÁnchez Morón. Ed. Tecnos SA. Madrid 1993, pp. 29-30.

${ }^{30}$ Vide nuestro trabajo «El principio de especialidad normativa [...]», especialmente, pp. 191-193.

${ }^{31}$ Lo destaca la STS de 22 de octubre de 1981 (RJ 1981\8073), cuando califica las normas sobre procedimiento sancionador de la LPA de 1958 (que se nomina por la propia LPA como procedimiento especial) como procedimiento común.
} 


\author{
administrativos (de los arts. 110 y siguientes de la Ley 30/1992), entre \\ otras ya citadas, porque regulan aspectos centrales o nucleares de los pro-
}

Y lo ha declarado expresamente la STC 87/1985, FJ $8^{\circ}$ : «el procedimiento sancionador habrá de atenerse al «administrativo común», cuya configuración es de exclusiva competencia estatal (art. 149.1.18 CE)».

En la doctrina científica ha resaltado lo anterior L. Cosculluela cuando indica que no debe identificarse procedimiento común con procedimiento general y afirma que el citado procedimiento especial de la LPA operaba como procedimiento especial común (en «La posición ordinamental de la Ley 30/1992 y los principios y efectos de la misma», en la obra colectiva titulada «Comentario sistemático a la Ley de Régimen jurídico de las Administraciones públicas y del Procedimiento Administrativo Común». Ed. Carperi. Madrid 1993, pp. 34-35).

Igualmente, E. GARCÍA DE ENTERRÍA y TOMÁS-RAMÓN FERNÁNDEZ sostienen que era una exigencia de la competencia del Estado sobre «procedimiento administrativo común» del art. 149.1.18 de la CE que la Ley 30/1992, a través de la cual se ejercita tal competencia, hubiera regulado el procedimiento sancionador común, como lo había hecho anteriormente la Ley de Procedimiento Administrativo de 1958. Y añaden que la deslegalización de tal procedimiento por el art. 134.1 de la referida Ley 30/1992 constituye una de las imperfecciones más clamorosas e injustificables de dicha Ley y que el Reglamento de procedimiento en materia sancionadora aprobado por RD 1398/1993 «carece de fuerza para imponerse como procedimiento administrativo común («Curso...», Tomo II, ed. 2004, p. 189).

Subraya E. GARCÍA DE ENTERRRÍA que, aunque el Preámbulo del Decreto dice que se cumple con la exigencia constitucional, al regular la Ley 30/1992 los principios del procedimiento sancionador, ello no es así, porque sus artículos 134 a 139 «no contienen una regulación del procedimiento sancionador, simplemente, sino una simple mención de algunas reglas de dicho procedimiento, no de sus «principios», como se nos pretende hacer creer (aunque, en todo caso, ya hemos notado que en la materia de procedimiento administrativo común la competencia estatal no es de simple regulación básica o de principio, sino de regulación integral)» («La problemática puesta en aplicación de la LRJ-PAC...». REDA 80, año 1993, epígrafe III).

Y, por otro lado, aunque el propio Preámbulo del Real Decreto 1398/1993, en su segundo párrafo, afirma que su «regulación responde a la consideración de que el procedimiento para el ejercicio de la potestad sancionadora se integra en el concepto de procedimiento administrativo común previsto en la Constitución para garantía del tratamiento coman a los ciudadanos», lo cierto es que, como resalta E. GARCÍA DE ENTERRÍA, «seguidamente intenta justificar la destrucción radical o voladura de tal «procedimiento administrativo común» en miles y miles de «procedimientos específicos» («La problemática puesta en aplicación de la LRJ-PAC...». REDA 80, año 1993, epígrafe III). Téngase en cuenta que, en su primer párrafo normativo, artículo 1.1, epígrafe «Objeto y ámbito de aplicación» dispone que «La potestad sancionadora se ejercerá mediante el procedimiento establecido en este Reglamento en defecto total o parcial de procedimientos específicos previstos en las correspondientes normas», lo que está en contradicción con una regulación estatal de «procedimiento administrativo común», aplicable a todas las Administraciones públicas.

Lo que encubre, en realidad, señala dicho Autor, «es una cláusula de total y absoluta «deslegalización» o degradación (supuesto que no se trata de una Ley) normativa: las normas que se enuncian podrán ser modificadas por cualquier norma dictada por cualquiera de esas Administraciones que tan generosamente se citan, y por normas, como es lo propio de la deslegalización, de rango inferior a la que contiene la cláusula. No es una deducción simplemente lógica, sino que el propio artículo 1, ahora párrafo 2, prevé expresamente «procedimientos sancionadores establecidos por ordenanzas locales», esto es, por normas reglamentarias del menor nivel. Esta conclusión puede extenderse a la propia Administración del Estado, que podrá establecer «procedimientos específicos» por simples Ordenes ministeriales y aun, probablemente, si ha de creerse lo 
cedimientos administrativos citados, aunque se puedan considerar especiales con respecto a las normas procedimentales generales del Título VI de la citada Ley.

Y estas normas de procedimiento administrativo común especiales (las que acabamos de enumerar, sin carácter exhaustivo), lo mismo que las de procedimiento administrativo común generales (las del Título VI de la Ley 30/1992), son directamente aplicables a las Comunidades Autónomas, como aspectos nucleares del procedimiento administrativo como institución, y no meramente en defecto de dichas normas autonómicas.

La relación general-especial opera dentro de las normas estatales de procedimiento administrativo común, de tal manera que, dentro de tales normas de procedimiento administrativo común, serán de aplicación preferente las especiales (p. ej. las de procedimiento sancionador) sobre las generales (las del Título VI de la Ley 30/1992). Pero, establecida tal preferencia interna, ambas normas son de aplicación directa (según tal prelación interna) y prevalente en relación con las normas procedimentales de las Comunidades Autónomas.

Así pues, si las normas procedimentales autonómicas están relacionadas con normas de procedimiento administrativo común especiales (p. ej., por ser sancionadoras), deberán ser respetuosas, en primer término, con las normas de procedimiento administrativo común especial de tal tipo (con las de los arts. 134 y ss. de la Ley 30/1992 y con las que debería incluir tal Ley de modo completo, como sostienen E. GARCÍA DE ENTERRÍA y TOMÁs-RAMÓN FERNÁNDEZ ${ }^{32}$ ) y, en segundo término, con las de procedimiento administrativo común general que se apliquen en defecto de las anteriores, pues todas ellas les son de aplicación directa y prevalente, por afectar a los aspectos nucleares del procedimiento administrativo como institución.

Pero es que incluso puede mantenerse que también poseen las normas de procedimiento administrativo común generales y especiales aplicación

que el Reglamento literalmente dice, por Instrucciones o Resoluciones de Direcciones Generales, siempre que se publiquen en el $B O E$ para que puedan ganar aplicabilidad general».

Y dicho Reglamento se dicta en virtud de la remisión que contienen el artículo 134 de la Ley 30/1992 y su Disposición final primera. Dado que ésta «faculta al Gobierno para dictar por Decreto cuantas medidas sean conducentes a la ejecución de lo dispuesto en esta Ley», es, pues, el Gobierno el órgano llamado a esa ejecución y, explícitamente, el Decreto la forma de ejercer tal competencia. Por ello, que ese Decreto se limite a presentarse como supletorio e intente trasladar tal competencia material a órganos inferiores de la Administración del Estado, así como a todas las Administraciones territoriales es, manifiestamente, una infracción de la delegación (Ob. cit., epígrafe II).

32 Véase lo expuesto en la nota al pie anterior. 
directa (según tal prelación interna) y prevalente en relación con las normas procedimentales del Estado que no tengan la condición de normas de procedimiento administrativo común, tal y como, acertadamente a nuestro entender, hemos visto que apunta L. PAREJO ALFONSO.

Y es que, en puridad, las demás normas procedimentales estatales especiales que no sean de procedimiento administrativo común no deberían poder aplicarse preferentemente sobre las generales o especiales de procedimiento común, si entran en contradicción con ellas, por constituir éstas las normas nucleares del procedimiento administrativo como institución y ser aplicables como mínimo común normativo que asegura la igualdad básica de los ciudadanos y las garantías mínimas de éstos en el procedimiento.

E, incluso, puede afirmarse aquí -como lo hace L. PAREJo Alfonsoque, cuando la Ley que regula el procedimiento administrativo común no tiene en cuenta lo anterior y excluye expresamente a normas procedimentales estatales que no son de procedimiento administrativo común de la sujeción a las que sí lo son, incurre en inconstitucionalidad, por no cumplir su función constitucional, por vulnerar el «principio de función constitucional» teorizado por R. GómEZ-FERRER MORANT ${ }^{33}$ y proclamado por nuestro Tribunal Constitucional, en sentencias tales como la 72/1984; 213/1988; 259/1988; 214/1989; 149/1991; 234/1999, FJ 5; 32/2000, FJ 5; 174/2000, FJ 4; y la 3/2003, FJ. $10^{34}$.

\footnotetext{
${ }^{33}$ R. GÓMEZ-FerRer Morant, «Relaciones entre Leyes: competencia, jerarquía y función constitucional». RAP 113, año 1.987, pp. 22 y ss. Y, antes, en «La posición de la Ley General Presupuestaria en el Ordenamiento jurídico», trabajo incluido en el libro «El marco jurídico-financiero del Sector público: Perspectivas de Reforma». Ix Jornadas de Control Financiero, celebradas en Madrid, del 22 al 24 de abril de 1986. Ministerio de Economía y Hacienda. Intervención General de la Administración del Estado. Madrid 1988.

${ }^{34}$ Ob. cit., pp. 30-32. Y se refiere aquí explícitamente a la exclusión por la Ley 30/1992 de su ámbito de aplicación de los procedimientos disciplinarios del personal al servicio de las Administraciones públicas (Disposición Adicional 8a); a la remisión a su normativa específica de la revisión en vía administrativa de los actos en materia tributaria (DA $5^{\text {a }}$.2) y de los actos de gestión recaudatoria de la Seguridad Social y la impugnación de los actos de la Seguridad Social y Desempleo (DA 6 ${ }^{\text {a }}$ ); a la aplicación tan sólo subsidiaria de la citada Ley a los procedimientos tributarios y de aplicación de los tributos (DA $5^{\text {a }}$.1) y a los procedimientos administrativos para la imposición de sanciones por infracciones en el Orden Social y para la extensión de actas de liquidación de cuotas de la Seguridad Social $\left(\right.$ DA $\left.7^{\mathrm{a}}\right)$.

En la misma línea, L. Cosculluela MontANER afirma que La Ley 30/1992 no ha respetado las exigencias del procedimiento administrativo común con tales exclusiones y las de las reclamaciones económico-administrativas (art. 107.4 de la Ley 30/1992), así como con la permisión a cualquier Administración pública de la determinación de los efectos positivos o negativos del silencio administrativo, que es un tema central en las garantías del administrado («Manual de Derecho Administrativo». Tomo I. Ed. Thomsom-Civitas, Madrid 2004, pp. 373-374).
} 
Más discutible, sin embargo, nos parece la afirmación de L. PAREJO ALFONSO de que las normas de procedimiento administrativo común sólo pueden aprobarse de una sola vez, en textos simultáneos (a diferencia de las normas básicas), excluyéndose la posibilidad de diversas normas de procedimiento administrativo común, ni siquiera por la especialidad de sus respectivos objetos ${ }^{35}$. Desde luego eso es lo deseable, en virtud del principio de seguridad jurídica, pero no creemos que hasta el punto de que pueda declararse inconstitucional una norma procedimental estatal especial que invoque el título de «procedimiento administrativo común», por ser aprobada extramuros de la Ley 30/1992.

6. Finalmente, queremos resaltar que el Tribunal Constitucional, al referirse a los aspectos centrales de los procedimientos englobables del título competencial «procedimiento administrativo común», a partir de su STC 227/1988, ha incluido aspectos del régimen jurídico de las Administraciones públicas que sólo pueden considerarse como procedimentales en un sentido amplio, como es el caso, a nuestro entender, de «los requisitos de validez o eficacia de los actos», que pueden pertenecer también al título competencial de regulación de bases del régimen jurídico de las Administraciones públicas ${ }^{36}$.

Y, aunque en una primera aproximación podría pensarse que la inclusión de estos aspectos (requisitos de validez y eficacia de los actos administrativos) en el título competencial del «procedimiento administrativo común» (de validez y eficacia) los blinda frente a su regulación por las Comunidades Autónomas, puesto que, si se incluyen en el título competencial general del «régimen jurídico de las Administraciones Públicas», admitirían ser alcanzados por la legislación de desarrollo de las Comunidades Autónomas sobre tal régimen, entendemos que el resultado final es el mismo.

Pues consideramos que tales aspectos siempre corresponden a la legislación básica estatal, ya sea por su carácter central o nuclear dentro del régimen jurídico de las Administraciones Públicas, que -como hemos

\footnotetext{
35 Ibidem, p. 31.

36 También acoge tal concepción amplia el Dictamen del Consejo de Estado 42.302, marginal 1257, Resumen de Doctrina Legal 1979-1991,BOE, Madrid 1993, p. 1143 y ss.
}

Y que tal concepción amplia puede superar la regulación del procedimiento administrativo común en sentido estricto lo reconoce la STC 50/1999, en su FJ 3a, pues, a pesar de suscribir por un lado tal criterio amplio, admite que no es reconducible al título "procedimiento administrativo común» la regulación que tan sólo de forma indirecta tiene repercusión o incidencia en el mismo ampliamente entendido o cuyo incumplimiento puede tener como consecuencia la invalidez del acto, pues esto obedece al título competencial sobre «régimen jurídico de las Administraciones Públicas». 
visto- también es caracterizador de lo básico según las SSTC 76/1986 y 103/1987), ya sea por entender que estamos ante una parte de dicho régimen que afecta al interés general de los españoles y no al interés particular de cada Comunidad Autónoma en relación con la disciplina del régimen de las Administraciones Públicas.

\section{LAS NORMAS PROCEDIMENTALES DE LA LEY 30/1992}

Si analizamos tales normas, podemos concluir que:

1) Responden perfectamente a las «normas de procedimiento administrativo común» cuyo significado hemos expuesto atrás, pues versan sobre cuestiones centrales, nucleares, del procedimiento como institución y de los procedimientos en general (estructura general del mismo, garantías generales de los ciudadanos ante él, modos de revisión de los actos administrativos y medios de ejecución de ésta) y no cuestiones secundarias, las denominadas por el Tribunal Constitucional «normas ordinarias de tramitación».

En tanto que Ley estatal podría haber incluido también cuestiones procedimentales secundarias aplicables a los procedimientos instrumentales de los regímenes sustantivos competencia del Estado, siempre que, en pro de la seguridad jurídica, hubiese matizado qué preceptos se dictaban en virtud de este último título, y cuáles otros en virtud del título competencial del «procedimiento administrativo común».

Los preceptos de procedimiento administrativo común serían aplicables a todas las Administraciones Públicas y todo tipo de procedimientos y las «normas ordinarias de tramitación» tan sólo serían vinculantes en relación con los procedimientos instrumentales de regímenes sustantivos de competencia del Estado, no en relación con los instrumentales de regímenes sustantivos de competencia de las Comunidades Autónomas.

2) En segundo lugar, incluyen normas de procedimiento administrativo común no sólo generales, sino también especiales o, expresado de otro modo, normas de procedimiento administrativo común que, a su vez, puede considerarse como general y normas de procedimiento administrativo común que, a su vez, puede calificarse de especial.

Ejemplo de lo primero son las normas procedimentales generales del Título VI de la Ley (art. 68 y siguientes) y de lo segundo las normas sobre 
procedimientos especiales para la sustanciación de los recursos administrativos (art. 110 a 113); para la revisión de oficio de los actos nulos de pleno derecho (art. 102 y 104); para la declaración de lesividad de los actos anulables favorables (art. 103); para las reclamaciones previas a la vía judicial civil (art. 122 a 126); para la ejecución de los actos administrativos (art. 96 y siguientes); para el ejercicio de la potestad sancionadora de las Administraciones Públicas(art. 134 y siguientes); y para la exacción de responsabilidad patrimonial de las Administraciones Públicas (arts. 142 a 144).

3) $Y$, en tercer lugar, puede decirse que las normas de procedimiento administrativo común, tanto generales (del título VI de la Ley 30/1992) como especiales (p. ej., para la sustanciación de los recursos), siguen más el modelo de los denominados procedimientos no formalizados que el de los formalizados, en tanto en cuanto no están totalmente escalonados, con preclusión de trámites, y las actuaciones y disposiciones que contempla no son todas obligatorias.

Aunque -como ya hemos precisado- algunas de ellas sí que son preceptivas (los requisitos de la solicitud del art. 70; el emplazamiento para la subsanación de la solicitud del art. 71, párrafos $1^{\circ}$ y $2^{\circ}$; la realización del trámite de audiencia cuando figuren en el procedimiento o deban ser tenidos en cuenta hechos, alegaciones y pruebas distintas de las aducidas por el interesado -como consigna el art. 84.4-) e introducen, asimismo, cierta secuencia obligatoria entre las actuaciones contempladas en las mismas (art. 84.1). Nos remitimos a lo expuesto atrás con mayor detalle.

En cualquier caso, hay que reseñar que otras normas de procedimiento administrativo común especiales, tales como las dedicadas a los procedimientos para el ejercicio de la potestad sancionadora, no se han decantado por el modelo de procedimiento formalizado o no formalizado en la Ley, pero va a ser después el Reglamento estatal respectivo, aprobado por el Real Decreto 1398/1993, el que efectúa la inclinación a favor del patrón de procedimiento formalizado, con una secuencia precisa totalmente obligatoria y preclusión de trámites. Si bien, tales normas procedimentales reglamentarias, como ya hemos expuesto atrás, ya no van a ser aplicables a las Comunidades Autónomas en todo caso, sino tan sólo respecto de aquellos regímenes sustantivos sobre los que el Estado tiene competencia normativa plena, como dispone el art. 1, letra b, de tal Real Decreto. Su consideración como normas de «procedimiento administrativo común» está descartada por el propio Reglamento, a pesar de que él mismo, en su Preámbulo, comienza afirmando que la regulación del procedimiento sancionador se integra en el concepto de «procedimiento administrativo común». 
4) Consideramos, en la línea defendida por E. GarCía DE EnTERRÍA y TOMÁs RAMÓN FERNÁNDEZ que, por formar parte del «procedimiento administrativo común», la regulación del procedimiento sancionador tenía que haber sido acometida directamente por la Ley 30/1992, con suficiente compleción, sin la deslegalización y degradación normativa efectuada y sin la apertura de competencias a las Comunidades Autónomas, a los entes locales, e incluso a órganos administrativos estatales que el Real Decreto 1398/1993 ha realizado, que no tienen apoyo alguno ni en la Constitución, ni en las propias leyes reguladoras de tales Administraciones.

5) Entendemos que es consistente la tesis atrás reseñada que afirma que la exclusión del ámbito de aplicación de dicha Ley de determinados procedimientos estatales o la previsión para otros, también estatales, de mera aplicación supletoria de la misma (Disposiciones Adicionales $5^{\mathrm{a}}, 6^{\mathrm{a}}$, $7^{\mathrm{a}}$ y $8^{\mathrm{a}}$ ) constituye una vulneración del principio de «función constitucional» reconocido por nuestra jurisprudencia constitucional y deben considerarse inconstitucionales en tal sentido, pues dichos procedimientos deben declararse totalmente sometidos a la regulación de los aspectos nucleares procedimentales que las normas de procedimiento administrativo común deben regular.

6) Como también consideramos asumible la tesis que recalca que la Ley 30/1992 no ha respetado las exigencias del «procedimiento administrativo común», cuando permite a cualquier Administración pública la fijación de los efectos positivos o negativos del silencio administrativo, a pesar de ser ésta una cuestión central en las garantías del administrado.

7) Y, finalmente, nos sumamos a la opinión de quienes mantienen que la Ley 30/1992 debería haber regulado como procedimiento administrativo común los aspectos nucleares del procedimiento de elaboración de los reglamentos de cualesquiera Administraciones públicas, en la línea que viene a reconocer la STC 204/1992, FJ. $5^{\circ}$, que, a nuestro entender viene a rectificar la afirmación tajante de la STC 15/1989 según la cual la regulación de tal procedimiento no forma parte del procedimiento administrativo común. 